\title{
Resistance to classical scrapie in experimentally challenged goats carrying mutation K222 of the prion protein gene
}

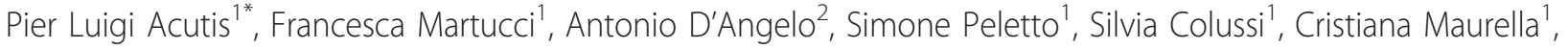 \\ Chiara Porcario ${ }^{1}$, Barbara Iulini', Maria Mazza ${ }^{1}$, Luana Dell'Atti ${ }^{1}$, Fabio Zuccon ${ }^{1}$, Cristiano Corona', Nicola Martinelli ${ }^{3}$, \\ Cristina Casalone ${ }^{1}$, Maria Caramelli ${ }^{1}$ and Guerino Lombardi ${ }^{3}$
}

\begin{abstract}
Susceptibility of sheep to scrapie, a transmissible spongiform encephalopathy of small ruminants, is strongly influenced by polymorphisms of the prion protein gene (PRNP). Breeding programs have been implemented to increase scrapie resistance in sheep populations; though desirable, a similar approach has not yet been applied in goats. European studies have now suggested that several polymorphisms can modulate scrapie susceptibility in goats: in particular, PRNP variant K222 has been associated with resistance in case-control studies in Italy, France and Greece. In this study we investigated the resistance conferred by this variant using a natural Italian goat scrapie isolate to intracerebrally challenge five goats carrying genotype Q/Q 222 (wild type) and five goats carrying genotype $\mathrm{Q} / \mathrm{K}$ 222. By the end of the study, all five Q/Q 222 goats had died of scrapie after a mean incubation period of 19 months; one of the five Q/K 222 goats died after 24 months, while the other four were alive and apparently healthy up to the end of the study at 4.5 years post-challenge. All five of these animals were found to be scrapie negative. Statistical analysis showed that the probability of survival of the Q/K 222 goats versus the Q/Q 222 goats was significantly higher $(p=0.002)$. Our study shows that PRNP gene mutation K222 is strongly associated with resistance to classical scrapie also in experimental conditions, making it a potentially positive target for selection in the frame of breeding programs for resistance to classical scrapie in goats.
\end{abstract}

\section{Introduction}

Scrapie is a naturally occurring transmissible spongiform encephalopathy (TSE) of sheep and goats, characterized by the accumulation in the central nervous system (CNS) of an abnormal isoform $\left(\mathrm{PrP}^{\mathrm{Sc}}\right)$ of a host-encoded cellular prion protein $\left(\mathrm{PrP}^{\mathrm{C}}\right)$ [1]. Natural scrapie in goats was first reported in France [2], followed by other cases worldwide: a state of the art review on goat scrapie in the European Union, including its epidemiology, was published by Vaccari et al. [3]. Goats are susceptible not only to classical scrapie, but also atypical/Nor98 scrapie cases have been detected. As in sheep, it is characterized by distinctive features in epidemiology (i.e., occurrence as single cases in the affected herds), molecular pattern,

\footnotetext{
* Correspondence: pierluigi.acutis@izsto.it

'CEA, Italian Reference Laboratory for TSEs, Neuroscienze - Istituto Zooprofilattico Sperimentale del Piemonte, Liguria e Valle d'Aosta, Via Bologna 148, 10154 Torino, Italy

Full list of author information is available at the end of the article
}

and distribution of histopathological changes [3]. Moreover, the only two confirmed cases of natural bovine spongiform encephalopathy (BSE) in small ruminants were reported in goats in France [4] and in a retrospective study in the UK [5].

The first Italian case of scrapie in the goat was diagnosed in 1997 [6]; since then, 65 outbreaks have occurred (51 of classical scrapie and 14 of Nor98 scrapie), in which 13000 goats were culled in accordance with the foreseen measures for eradication of the disease.

Although an infectious disease, the susceptibility of sheep to scrapie is strongly influenced by polymorphisms of the prion protein gene (PRNP). PRNP haplotypes valine/arginine/glutamine (VRQ) and alanine/arginine/ glutamine (ARQ) at codons 136, 154, 171, respectively, are associated with high susceptibility to classical scrapie, whereas the ARR haplotype has been linked to
C Biomed Central

() 2012 Acutis et al; licensee BioMed Central Ltd. This is an Open Access article distributed under the terms of the Creative Commons Attribution License (http://creativecommons.org/licenses/by/2.0), which permits unrestricted use, distribution, and reproduction in any medium, provided the original work is properly cited. 
resistance [7-10]. Accordingly, the EU has implemented breeding programs to increase scrapie resistance in sheep populations. In compliance with regulation (EC) 999/2001, as amended, several Member States are now increasing the frequency of the ARR haplotype. A similar approach has not yet been applied in goats, but it would be desirable in this species too, given that scrapie poses a problem for the economy and animal welfare, and that goats, often bred in mixed flocks with sheep, can play a role in maintaining the circulation of scrapie strains and the consequent sheep exposure. Genetic analysis of the goat PRNP gene revealed 46 polymorphisms in the open reading frame $[3,11]$, including silent mutations and a PRNP variant containing three instead of the five usual octapeptide repeats [12]. Various European studies have suggested that several polymorphisms can modulate scrapie susceptibility in goats as well. The presence of methionine (M) at codon 142 is associated with increased incubation periods after experimental challenge of BSE and scrapie strains [13] and in natural scrapie outbreaks $[14,15]$. A reduced susceptibility to natural scrapie has also been reported for goats carrying arginine $(\mathrm{R})$ at codon 143, histidine $(\mathrm{H})$ at codon 154 $[16,17]$ or glutamine (Q) at codon 211 [14]. However, H154 has clearly been suggested to be a risk factor for Nor98 goat scrapie [18]. The most promising results have been obtained for codon 146, carrying serine (S) or aspartic acid (D), which is linked to high resistance in Cyprus $[19,20]$, and for codon 222, carrying lysine (K), which in Italy was first reported as conferring resistance and has only been associated with healthy animals $[16,21]$. An association of $\mathrm{K} 222$ with a protective effect was also later found in France and Greece [14,22]. Taken together, these results provide encouraging evidence for the support of breeding programs for resistance in goats against classical scrapie in all EU Member States, as stated by the EFSA Panel on Biological Hazards in the "Opinion on genetic TSE resistance in goats in all EU Member States" [23], and perhaps also in other non-EU countries. In such a prospective, it is essential to reinforce existing data from field studies with those from experimental studies, particularly those carried out with the experimental transmission of different TSE isolates in goats harbouring the PRNP alleles of interest.

In this study, we investigated the resistance given by mutation K222 by intracerebrally challenging two groups of goats, with and without the considered allele, using a natural Italian goat scrapie isolate. Our study confirms the highly protective effect of K222 against classical scrapie. Furthermore, being the first scrapie transmission study carried out in goats in Italy, it provides information on clinical signs and $\mathrm{PrP}^{\mathrm{Sc}}$ distribu- tion patterns in goats affected by an Italian scrapie strain.

\section{Materials and methods \\ Animals and animal care}

Ten four-month-old goats were purchased from two herds with no record of scrapie cases in the last five years: six animals were Camosciata cross-bred and four were dwarf goat cross-bred. The animals were chosen on the basis of their genotype and having been born in northern Italy near the study site. This was done to avoid problems of stress due to long transport or climatic changes. The animals were previously genotyped at the PRNP locus, as described below, and two groups were formed: one group consisted of five animals heterozygous for $\mathrm{Q} / \mathrm{K}$ at codon 222 , and one group of five wild type Q/Q 222 animals, with a mixed assortment of the genotype at codon 240 (Table 1). No K/K 222 goats were found. In both groups there were three Camosciata cross-bred and two dwarf goat cross-bred animals. No other mutations were present in the PRNP gene of these animals, except for the two Q/Q 222 dwarf goat crossbred animals that presented a deletion of two octarepeats, thus being 3/5 heterozygous for the octapeptide repeats. These animals were included in the study to also gather information on the possible resistance conferred by this deletion, as hypothesized by Goldmann et al. [12]. The animals were kept in the facility for one month before challenging to allow them to adapt to the new environment and to exclude the presence of other diseases. During the experiment, they were all kept in the same room to expose them to identical environmental conditions. All procedures involving the animals and their care were conducted in conformity with national and international laws and policies (EEC Council Directive 86/609, OJL358, 1, 12 December 1987; Italian Legislative Decree 116/92, Gazzetta Ufficiale della Repubblica italiana 10, 18 February 1992; and Guide for the Care and Use of Laboratory Animals, U.S. National Research Council, 1996).

\section{Genetic analysis}

Genomic DNA was isolated from EDTA-treated blood samples using Thermo Labsystems KingFisher kits (Thermo LabSystems Inc., Beverly, MA, USA). PCR amplification of the entire open reading frame of the PRNP gene was performed according to a previously described protocol [24] using the primers p8(+) (5'CAGGTTAACGATGGTGAAAAGCCACATAGG-3') and $99(-)$ (5'-GGAATTCTATCCTACTATGAGAAAAATGAGG-3') [8]. PRNP polymorphisms were detected by direct DNA sequencing on both strands of the PCR products by using dye terminator cycle sequencing and an ABI Prism 3130 Genetic Analyser (Applied 
Table 1 Goats included in the study: survival time and duration of symptoms after i.c. challenge.

\begin{tabular}{|c|c|c|c|c|c|c|}
\hline Ear tag & Sex & Breed & Genotype & Scrapie positivity & Survival time (days) & Symptomathology duration (days) \\
\hline 1 & $\mathrm{~F}$ & Camosciata cross-bred & $\begin{array}{l}\mathrm{Q} / \mathrm{Q} 222 \\
\mathrm{P} / \mathrm{P} 240\end{array}$ & yes & 553 & 5 \\
\hline 12 & $\mathrm{~F}$ & Dwarf goat cross-bred & $\begin{array}{c}\text { 3/5 repeats } \\
\text { Q/Q222 } \\
\text { S/P240 }\end{array}$ & yes & 539 & 23 \\
\hline 14 & M & Dwarf goat cross-bred & $\begin{array}{c}\text { 3/5 repeats } \\
\text { Q/Q222 } \\
\text { S/P240 }\end{array}$ & yes & 539 & 13 \\
\hline 18 & $\mathrm{~F}$ & Camosciata cross-bred & $\begin{array}{l}\text { Q/Q222 } \\
\text { S/P240 }\end{array}$ & yes & 477 & 14 \\
\hline \multirow[t]{2}{*}{ VA2 } & $\mathrm{F}$ & Camosciata cross-bred & $\begin{array}{l}\mathrm{Q} / \mathrm{Q} 222 \\
\mathrm{~S} / \mathrm{S} 240\end{array}$ & yes & 734 & 2 \\
\hline & & & \multicolumn{4}{|c|}{ Mean value: $569( \pm 97)$} \\
\hline 7 & M & Dwarf goat cross-bred & $\begin{array}{l}\mathrm{Q} / \mathrm{K} 222 \\
\mathrm{~S} / \mathrm{P} 240\end{array}$ & no & 1643 & / \\
\hline $14 \mathrm{R}$ & $\mathrm{F}$ & Camosciata cross-bred & $\begin{array}{l}\mathrm{Q} / \mathrm{K} 222 \\
\mathrm{~S} / \mathrm{S} 240\end{array}$ & no & 720 & / \\
\hline 17 & $\mathrm{~F}$ & Dwarf goat cross-bred & $\begin{array}{l}\mathrm{Q} / \mathrm{K} 222 \\
\mathrm{~S} / \mathrm{S} 240\end{array}$ & no & 1643 & / \\
\hline 29 & $\mathrm{~F}$ & Camosciata cross-bred & $\begin{array}{l}\mathrm{Q} / \mathrm{K} 222 \\
\mathrm{~S} / \mathrm{P} 240\end{array}$ & no & 1643 & / \\
\hline 32 & $\mathrm{~F}$ & Camosciata cross-bred & $\begin{array}{l}\text { Q/K222 } \\
\text { S/P240 }\end{array}$ & no & 1643 & / \\
\hline
\end{tabular}

Biosystems, Carlsbad, CA, USA). Sequencing primers were $\mathrm{p} 8(+), \quad \mathrm{p} 61(+) \quad\left(5^{\prime}\right.$-AACCAACATGAAGCATGTGG-3'), p60(-) (5'-GATAGTAACGGTCCTCATAG-3') and p9(-)[7]. The primers were hybridized to the target PRNP DNA at codons 1-7, 109-116, 147-154 and 249-257, respectively, (ovine reference sequence GenBank accession number AJ000739).

\section{Inoculum preparation and inoculation}

The inoculum was prepared from the brain tissue of a female goat affected by natural classical scrapie (according to the approved discriminatory immunoblot carried out by the Istituto Superiore di Sanità, Rome, Italy) with genotype of the PRNP gene heterozygous at codon 240 $(\mathrm{S} / \mathrm{P})$ and with no other mutations. The inoculum was ground in a mechanical grinder and homogenized with normal sterile saline solution to a final concentration of $10 \%(\mathrm{w} / \mathrm{v})$. A solution of penicillin and streptomycin was added to the inoculum prior to use and the homogenate was checked for microbiological sterility. Just prior to inoculation, the animals were clinically examined to rule out clinical abnormalities. Intracerebral inoculation of the kids was performed as previously described [25] with minor modifications. Briefly, the animals were anaesthetized with xylazine $(50 \mu \mathrm{g} / \mathrm{kg})$ and, in surgical aseptic conditions, a midline incision was made in the skin at the junction of the parietal and frontal bones and a $1 \mathrm{~mm}$ hole was drilled through the calvarium. The inoculum $(0.5 \mathrm{~mL}$ of $10 \% \mathrm{w} / \mathrm{v}$ brain homogenate) was injected into the midbrain through a 22 gauge, $9 \mathrm{~cm}$ long needle while withdrawing the needle from the brain. The skin incision was closed with a single suture. The inoculated animals were housed together in a bio-safety level 3 containment facility.

\section{Clinical evaluation}

Clinical evaluation comprised daily observation and biweekly physical assessment carried out by the animal husbandry staff and the veterinarian, respectively. Neurologic examination was performed monthly by a boardcertified neurologist. For this purpose, a clinical examination protocol, previously used for sheep [26], was applied. The protocol followed the standard procedure for assessing mental status, posture, gait, postural reactions and proprioception, cranial nerves, spinal reflexes and sensitivity. Sensitivity to external stimuli was evaluated by light and acoustic response, as described for BSE [27], wherein an animal was considered hyperreactive if it showed an exaggerated response three times in a row. The nibble reflex was defined as positive if the animal showed head and neck extension, chewing movements associated with head and tongue movements after being manually stimulated on the withers and lumbosacral areas.

An animal was considered symptomatic (onset of symptoms) if it showed at least two of the following criteria: abnormal fleece, abnormal mental status/behaviour, abnormal gait, abnormal postural reaction/ propioception and positive nibble reflex. Neurologic examinations were intensified according to the onset of 
symptoms. Animals that became inappetant or tended toward recumbency were humanely euthanized.

\section{Tissue sample collection}

After general anaesthesia with propofol (PropoVet ${ }^{\circledR}$, Abbott, Illinois, USA) administered intravenously (i.v.), the animals were euthanized with i.v. injected Enbutramide/Mebezonium iodide/Tetracaine hydrochloride $\left(\operatorname{Tanax}^{\circledR}\right.$, Intervet Inc. Merck, Summit, NJ, USA). After culling of the animals, the whole brain, the entire spinal cord, and the lymph reticular system were collected and divided into two halves, one was frozen at $-80^{\circ} \mathrm{C}$ for immunoblot analyses and the other was fixed in $4 \%$ buffered formalin for immunohistopathological examinations. A further panel of peripheral organs and tissues was collected and frozen at $-80^{\circ} \mathrm{C}$ for immunoblot analyses (Table 2).

\section{Immunoblot analysis}

\section{Pre-treatment for extraneural tissues}

Extraneural tissues, not including the spleen, were cut into small pieces by means of scalpels and incubated in a PBS-1\% trypsin solution overnight at room temperature (RT) under gentle agitation. After incubation, the tissues were rinsed with ultrapure water [28]. From the authors' experience, trypsin digestion did not reduce the amount of detectable $\operatorname{PrP}^{\mathrm{sc}}$.

\section{PrP extraction method}

Ten percent $(\mathrm{w} / \mathrm{v})$ homogenates from different brain areas and extraneural tissues were prepared in lysis buffer $(10 \%$ N-lauroylsarcosine diluted in Tris Buffer Saline $\mathrm{pH}$ 7.4) and clarified by centrifugation at $22000 \mathrm{~g}$ for
$20 \mathrm{~min}$ at $10^{\circ} \mathrm{C}$ (Ultracentrifuge Optima TLX, Rotor TLA 55, Beckman Coulter, Fullerton, CA, USA). For extraneural tissues a further step was added in which supernatant was collected and incubated with benzonase nuclease $50 \mathrm{meq} / \mathrm{mL}$ (Novagen, San Diego, CA, USA) for $30 \mathrm{~min}$ at $37^{\circ} \mathrm{C}$. The supernatants were incubated with proteinase K (PK; $40 \mu \mathrm{g} / \mathrm{mL}$; Sigma Aldrich, Poole, Dorset, UK) for $1 \mathrm{~h}$ at $37^{\circ} \mathrm{C}$ under continuous shaking. After centrifugation at $215000 \mathrm{~g}$ for $1 \mathrm{~h}$ at $10^{\circ} \mathrm{C}$ (Ultracentrifuge Optima TLX, Rotor TLA 110, Beckman Coulter), the pellet was dissolved in Laemmli buffer and boiled for $10 \mathrm{~min}$ at $99^{\circ} \mathrm{C}$.

\section{Electrophoresis and immunodetection method}

Samples were subjected to sodium dodecyl sulphate polyacrilamide gel electrophoresis on a $12 \%$ handmade minigel (acrylamide/bisacrylamide ratio 37.5:1) and then transferred to a polyvinylidene fluoride membrane (PVDF) (Immobilion P, Millipore, Billerica, MA, USA) by wet blotting. $\operatorname{PrP}^{\mathrm{Sc}}$ was detected by the $\mathrm{P} 4(0.1 \mu \mathrm{g} /$ mL; R-Biopharm, Darmstadt, Germany) [29] monoclonal antibody and an anti-mouse antiserum conjugated with alkaline phosphatase. Reaction was revealed by a chemiluminescent substrate (Immun-Star, Bio-Rad, Hercules, CA, USA) and visualised on Hyperfilm ECL (GE-Healthcare Ltd., St. Giles, UK) or by a gel documentation analysis system (UVI Prochemi, Uvitec, Cambridge, UK). Comparison of the molecular masses of the $\mathrm{PrP}^{\mathrm{Sc}}$ bands was carried out on the inoculated goats and inoculum sample. For quantitative study of the glycoform ratios, chemiluminescent signals corresponding to the three glycoforms of $\mathrm{PrP}^{\mathrm{Sc}}$ were quantified using a UVI Prochemi analysis system. Glycoform ratios were expressed

Table 2 Tissues collected at necropsy.

\begin{tabular}{|c|c|c|c|c|c|}
\hline $\begin{array}{l}\text { Central nervous } \\
\text { system }\end{array}$ & $\begin{array}{l}\text { Lymph reticular } \\
\text { tissues }\end{array}$ & Respiratory tract & $\begin{array}{l}\text { Gastro- } \\
\text { intestinal tract }\end{array}$ & Muscles & Miscellaneous \\
\hline Encephalon & Tonsil & Trachea & Salivary glands & Tongue & Eye \\
\hline Cerebellum & $\begin{array}{l}\text { Retropharyngeal } \\
\text { lymph node }\end{array}$ & Lung & Esophagus & Masseter muscle & Kidney \\
\hline Brainstem & $\begin{array}{l}\text { Mandibular lymph } \\
\text { node }\end{array}$ & $\begin{array}{l}\text { Olfactory tract at nasal septum, ethmoturbinates and } \\
\text { ventral nasal concha }\end{array}$ & Liver & $\begin{array}{l}\text { Biceps brachii } \\
\text { muscle }\end{array}$ & $\begin{array}{l}\text { Urinary } \\
\text { bladder }\end{array}$ \\
\hline $\begin{array}{l}\text { Cervical spinal } \\
\text { cord }\end{array}$ & $\begin{array}{l}\text { Mesenteric lymph } \\
\text { node }\end{array}$ & & Rumen & $\begin{array}{l}\text { Triceps femoris } \\
\text { muscle }\end{array}$ & $\begin{array}{l}\text { Mammary } \\
\text { gland }\end{array}$ \\
\hline $\begin{array}{l}\text { Thoracic spinal } \\
\text { cord }\end{array}$ & Spleen & & Omasum & Heart & Adrenal gland \\
\hline \multirow[t]{8}{*}{$\begin{array}{l}\text { Lumbar spinal } \\
\text { cord }\end{array}$} & $\begin{array}{l}\text { Third eyelid } \\
\text { lymphoid tissue }\end{array}$ & & Reticulum & & \\
\hline & & & Abomasum & & \\
\hline & & & Duodenum & & \\
\hline & & & Jejunum & & \\
\hline & & & Ileum & & \\
\hline & & & Ileo-ciecal valve & & \\
\hline & & & Caecum & & \\
\hline & & & Rectum & & \\
\hline
\end{tabular}


as mean percentages of the total signal for the three glycoforms (di-, mono-, and un-glycosylated) from three different runs of the samples.

\section{$\operatorname{PrP}^{\mathrm{Sc}}$ quantification}

In order to estimate the relative concentration of $\mathrm{PrP}^{\mathrm{Sc}}$ in some positive extraneural organs (skeletal muscle, intestinal tract, omasum, abomasum, kidney), the signal intensity was quantified. Specifically, we compared the intensity of the proteinase- $\mathrm{K}$ digested positive signals with calibration curves obtained by diluting the corresponding brainstem of the scrapie-positive goat with scrapie-negative homogenates of the above-mentioned extraneural tissues. This comparison was done with three of the scrapie-positive animals. The extraction method and immunoblot technique were identical to those previously described. Quantification analyses were performed using the UVI Prochemi gel documentation and analysis system.

\section{Immunohistochemical analysis}

Immunohistochemical investigations for $\mathrm{PrP}^{\mathrm{Sc}}$ were performed on each brain area and lymph reticular tissue. Four- $\mu$ m-thick sections of each formalin-fixed, paraffinembedded specimen were cut. The slides were dewaxed and rehydrated by routine methods and then immersed in $98 \%$ formic acid for $25 \mathrm{~min}$. After washing in distilled water, the sections were autoclaved for $30 \mathrm{~min}$ at $121^{\circ} \mathrm{C}$ in citrate buffer ( $\mathrm{pH}$ 6.1). Endogenous peroxidase activity was blocked in 3\% hydrogen peroxide for $20 \mathrm{~min}$ at RT. To block non-specific tissue antigens, the sections were incubated with $5 \%$ horse blocking serum for $20 \mathrm{~min}$ at RT and then incubated for $1 \mathrm{~h}$ at RT with primary monoclonal antibody L42 (epitope GNDYEDRYYRENMYRYPNQ, amino acids 145 to 163 of the ovine PrP, 1: 250 dilution; RIDA, R-Biopharm, Darmstadt, Germany) [30]. After rinsing, a biotinylated goat anti-mouse secondary antibody (1: 200 dilution; Vector Laboratories, Burlingame, CA, USA) was applied to the tissue sections for 30 min at RT, followed by the avidin-biotinperoxidase complex (Vectastain ABC kit; Vector Laboratories), according to the manufacturer's protocol. $\mathrm{PrP}^{\mathrm{Sc}}$ immunoreactivity was visualized using 3,3'-diaminobenzidine (Dakocytomation, Carpinteria, CA) as a chromogen; the sections were then counterstained with Meyer's haematoxylin. In case of a positive result, specificity was checked by replacing the primary antibody by normal serum.

\section{Statistical analysis}

Survival times between the two groups were compared using Kaplan-Meier survival estimates. The difference in the probability of survival was analyzed using the logrank test for equality of survivor functions.

\section{Results}

By the end of the study, all the susceptible Q/Q 222 goats had died or been euthanized for animal welfare after a mean incubation period of 19 months $(569 \pm 97$ days). Survival times are shown in Table 1. All were shown to be scrapie positive by both immunoblot and immunohistochemistry. In the group of supposedly resistant Q/K 222 goats, one animal died of unknown cause 24 months into the study. All the other animals were alive and apparently healthy up to the end of the study, when they were euthanized, i.e., at 4.5 years postchallenge (Table 1). All five animals, including the one dead at 24 months post-challenge, were shown to be scrapie negative by immunoblot and immunohistochemistry of both the CNS and the lymph reticular system. Statistical analysis shows that the probability of survival of the Q/K 222 goats versus the Q/Q 222 goats was significantly higher $\left(\chi^{2}=9.34, p=0.002\right)$.

At clinical examination, three animals (ear tag 18, 1 and VA2) showed itching, skin lesions, depressed mental status, wide base stance, tremors, ataxia, weakness and abnormal postural reactions/proprioception. Two animals (ear tag 12 and 14) developed, in addition to skin lesions, depression and tremors, a central vestibular syndrome manifested by head tilt, wide base stance, asymmetrical ataxia and circling, ipsilateral paresis and proprioceptive deficits, vertical nystagmus, positional strabismus, bilaterally decreased menace reaction and normal palpebral reflex. Table 1 reports the duration of the symptoms.

All five Q/Q 222 animals tested positive for the CNS and the large part of the lymph reticular system analysed both by Western blot and immunohistochemistry. Moreover, the peripheral nerves and numerous extraneural organs tested scrapie positive by Western blot (Table 3). Molecular analysis of $\mathrm{PrP}^{\mathrm{Sc}}$ of the inoculated goats and the inoculum sample revealed a similar electrophoretic pattern characterized by three bands corresponding to the di-, mono- and un-glycosylated forms, with a molecular weight of 30, 25 and $20 \mathrm{kDa}$, respectively. The mean ( \pm standard deviation $[\mathrm{SD}]$ ) di-, monoand un-glycosylated band intensity was $48.16 \pm 2: 31.86$ $\pm 2: 19.98 \pm 1.9$, respectively, for the inoculated goats and $49.27 \pm 1.5: 32.19 \pm 1.1: 18.54 \pm 2$, respectively, for the inoculum sample. Quantification showed that the $\mathrm{PrP}^{\mathrm{Sc}}$ signal intensity in the positive muscular tissues was generally similar to that obtained when five milligrams of the corresponding positive brainstem homogenate were diluted in five grams of a negative muscle homogenate. From this finding, we estimated that the $\mathrm{PrP}^{\mathrm{Sc}}$ levels in the three examined cases were lower than those found in the corresponding brainstems by a factor of approximately $1 \times 10^{-3}$. The signal intensities 


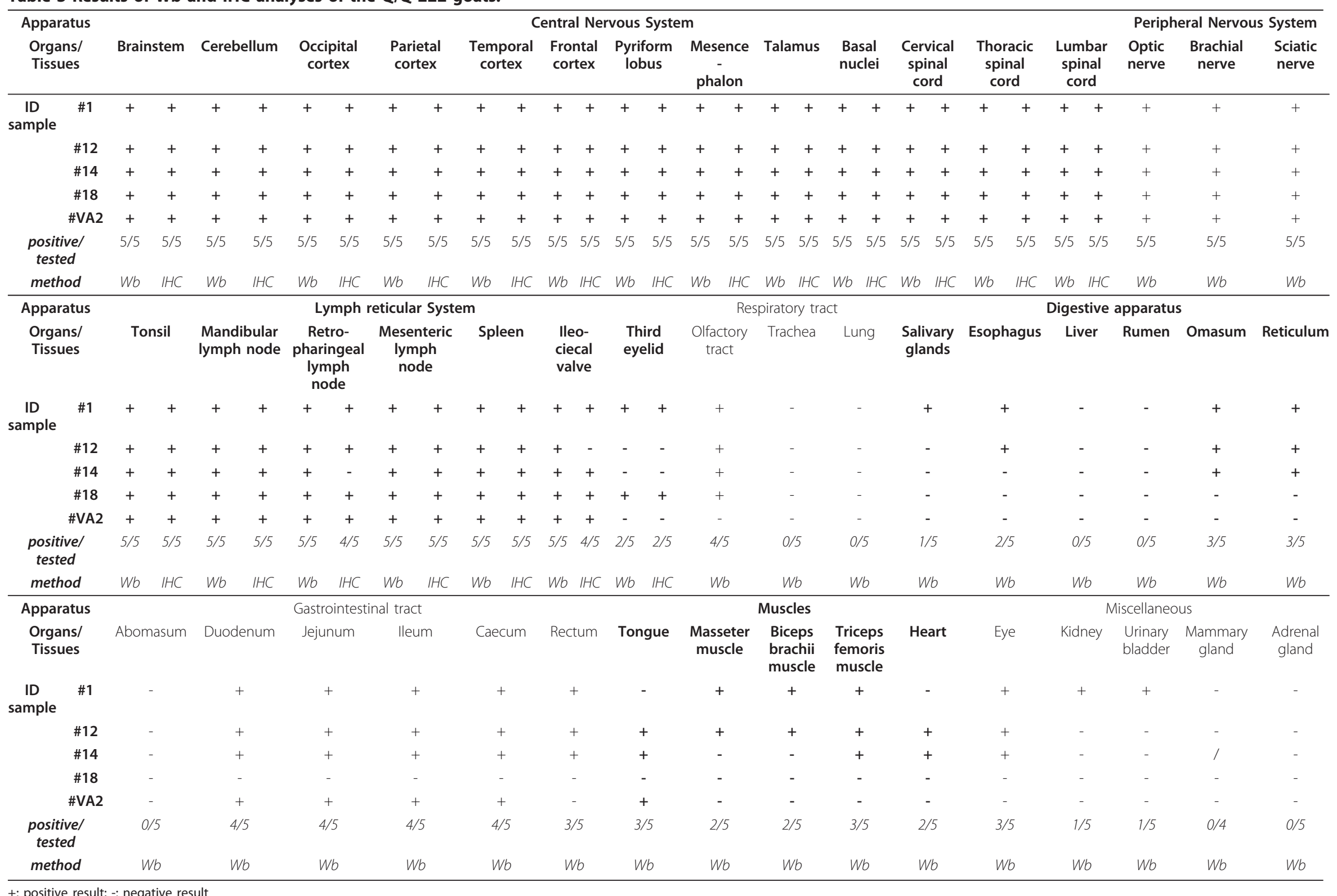


of the positive omasum, abomasum and kidney were usually lower than those found in the corresponding brainstems by a factor of $1 \times 10^{-3}-1 \times 10^{-4}$.

The $\mathrm{Q} / \mathrm{K} 222$ goats were completely negative by immunoblot analysis of all extraneural tissues and organs.

\section{Discussion}

Our study shows that PRNP gene mutation K222 is strongly associated with resistance to classical scrapie in experimentally challenged goats, confirming the results previously obtained in field studies $[16,21]$. The $\mathrm{Q} / \mathrm{K}$ 222 goats arrived as healthy, scrapie negative until the end of the study, with a significantly longer survival time of about three years compared to the Q/Q 222 inoculated goats. The study had to be necessarily concluded, but the survival time of 1643 days (i.e. 4.5 years), which is nearly equal to the average economic lifespan of a goat in Italy (i.e. five years), was long enough to allow the hypothesis for a high level of resistance, even if a minimal susceptibility or a very prolonged incubation period (i.p.) cannot be excluded. Admittedly, the transmission of infection was carried out in conditions where the host barriers were reduced to a minimum, via the intracerebral route and by inoculating with a goat natural scrapie isolate that was thus already adapted to the species. Nonetheless, the $\mathrm{Q} / \mathrm{K}$ 222 goats remained healthy for a longer period than the i.p. reported in other transmission studies in goats and sheep. Heterozygous goats with the partial resistanceassociated M142 mutation succumbed much earlier, at 984-985, 675-894 and 640-895 days, after i.c. transmission of BSE, sheep scrapie CH1641 and sheep-passaged ME7, respectively. In wild type goats, instead, the same strains had an i.p. similar to that obtained in the present study [13]. Similarly, Foster et al. [31] reported in wild type goats i.c. challenged with natural scrapie and BSE, an i.p. of 362-517 and 506-570 days, respectively. In sheep, i.c. BSE challenged ARR/ARR animals showed an i.p. of 1008-1127 days post-infection [32]. However, because our study showed the resistant goats still healthy, it cannot be excluded that they might have remained scrapie negative for their entire normal life span.

The results of the challenge of the Q/Q 222 goats yielded further interesting information on goat scrapie genetics. The two goats carrying the octarepeat deletion died of scrapie, with an i.p. not unlike that of the other goats in the same group, showing that in our sample this mutation did not confer any resistance, on the contrary to that which was hypothesized by Goldmann [12], perhaps because of the scrapie strain used in the experiment. It is noteworthy that one Q/Q 222 goat (VA2) died after an i.p. nearly 200 days longer than that of the rest of the same group. This goat had no other mutation on the PRNP gene, but it was the only one out of its group that was homozygote for serine at codon 240 . While this prolonged i.p. in one animal does not allow us to say whether it was significant or just happened by chance, we can speculate that other unknown genetic factors may have come into play or that indeed serine at codon 240 could have had an effect. Field studies have produced controversial results about codon 240 , indicating a positive association with scrapie infection of P240 [21] or a positive association with clinical disease of S240 [22] or no association [13,16,17]. Interestingly, Goldmann et al. [13] reported that a BSE orally challenged S/S 240 goat had an i.p. 500 days longer than an S/P240 goat. Barillet et al. [14] found that mutation M142 in heterozygotes conferred a protective effect only when in association with $\mathrm{P} / \mathrm{P} 240$ homozygotes. Although codon 240 is generally not believed to influence scrapie susceptibility, it could exert an effect, perhaps depending on the scrapie strain involved.

The clinical signs seen in three of the five scrapie positive animals were similar to those previously described in both experimental and natural scrapie, but none of the animals in the present study showed aggressiveness, hypersensitivity to external stimuli or hyperexcitability. As already known in goats, unlike that observed in sheep with scrapie, [31,33-35], scratching of the animal's back did not elicit the nibble reflex in any goat. Worth noting was the lateralization of clinical signs in the two remaining animals (ear tag 12 and 14), suggesting an involvement of the vestibular system. Histopathological examination of the brain ruled out a secondary disease that could have caused the asymmetrical clinical presentation. A vestibular syndrome in two goats with classical scrapie was described by Konold et al. [34]. This atypical clinical presentation stresses the importance of not excluding scrapie on the basis of lateralization of neurological signs in experimental and field conditions.

Since the route of inoculation differed from that of the natural disease, no conclusions on the pathogenesis of scrapie in goats can be drawn from the pattern of $\operatorname{PrP}^{\mathrm{Sc}}$ distribution in the extraneural tissues; nonetheless, it does give information on the centrifugal diffusion of $\operatorname{PrP} \mathrm{P}^{\mathrm{Sc}}$, which may prove useful for risk assessment of human exposure given by peripheral districts. Our results are in line with previous observations in goats and sheep with natural scrapie or after oral challenge. It appears that $\mathrm{PrP}^{\mathrm{Sc}}$ had a widespread distribution, similar to that observed in sheep, involving the lymph reticular system, as already known in goats [36], and other districts, some of which have never been reported in goats so far, such as the omasum, abomasum, kidney and the olfactory system, have already been reported to be sites 
of $\mathrm{PrP}^{\mathrm{Sc}}$ deposition in sheep $[37,38,28]$. Similarly to what has been found recently in naturally affected sheep and goats [39], scrapie positivity was not found in the third eyelid or the rectal mucosa in all the animals, highlighting the limitation of using those districts for preclinical diagnosis, as recently proposed $[40,41]$.

The finding of positive signals in the skeletal muscles in three of the five scrapie-positive goats is consistent with reports of muscle tissues that tested positive in a scrapie i.c. challenged goat [42] and orally challenged goats older than 21 months [43]. The $\operatorname{PrP}^{\mathrm{Sc}}$ amount, compared to that in the brainstem, was at least 1000fold lower in the muscles and 1000 to 10 000-fold lower in the omasum, abomasum and kidney, suggesting a low risk for human transmission by these tissues.

After identifying a genetic variant associated with TSE resistance, the main question is the validity of the association in relation to different classical scrapie strains, atypical scrapie and BSE. Our study confirms that variant K222 of the goat PRNP gene can be a genetic target to select for in the frame of breeding programs for the control and eradication of classical scrapie in goats. This result is certainly mainly valid for Italy, given that an Italian scrapie isolate was used in the experiment. The situation in Italy could be particularly favorable because there is good evidence for a low variability of circulating scrapie strains $[44,45]$. The association of K222 with resistance found in field studies in France and Greece indicates that this variant can probably confer resistance to several classical scrapie strains. Moreover, a recent study showed that cell-free conversion of recombinant PrP was completely abolished in the presence of the recombinant K222 variant, using mouse scrapie strain ME7 [46]. On the contrary, some positive Q/K 222 goats were recently detected in Greece, with some evidence that they could be affected by a scrapie strain different from those previously studied in Italy, France and Greece, from which K222 carriers could not have been protected [11]. No data are currently available regarding the K222 variant and BSE and atypical scrapie. In Italy, a Nor98 positive goat carrying K222 in linkage with H154 was found, suggesting that K222 might not confer resistance to atypical scrapie [18]. Similarly, in a highly scrapie-affected Greek herd, a unique C- and N-terminally truncated protease resistant PrP fragment, which has been suggested to be a marker of an unrecognized prion protein disorder, was identified in clinically healthy goats, including Q/K 222 animals as well [47].

One limitation of the present study was the lack of homozygous K/K222 animals. The role of homozygotes needs to be investigated to verify whether there could be a situation like that in sheep, where ARR/ARR animals are highly resistant, while some cases of disease are occasionally reported in ARR/XXX [48]. Barillet et al.
[14] estimated the risk for $\mathrm{Q} / \mathrm{K} 222$ goats as being within a similar range as the risk for ARR/ARQ sheep, comparing them to their respective wild type genotypes. Moreover, the study on cell-free conversion showed that recombinant K222 alone abolished conversion and significantly reduced conversion in a condition of simulated heterozygosis, i.e., in co-incubation with another PrP variant [46]. These results thus suggest that $\mathrm{K} / \mathrm{K}$ 222 homozygotes should be more resistant than heterozygotes against classical scrapie, even if only experimental challenges can exclude the possible phenomenon of overdominance, as observed in the susceptibility of mice to several scrapie strains [49].

Another open question in the present study is whether negative K222 goats can be healthy carriers of infection. To answer this, the negative tissues of the challenged Q/K 222 goats will be tested by bioassay for the presence of infectivity.

Other experimental challenge studies on the K222 variant are underway in Europe [23]. If they obtain the same results as ours in other breeds and with other strains including BSE, it will be possible to implement breeding programs to control classical scrapie in goats in the near future.

\section{Acknowledgements}

This work was supported by Italian Ministry of Health grant IZSPLV 14/05 and by the EU project Goat-BSE (FOOD-CT-2006-36353).

\section{Author details}

${ }^{1}$ CEA, Italian Reference Laboratory for TSEs, Neuroscienze - Istituto Zooprofilattico Sperimentale del Piemonte, Liguria e Valle d'Aosta, Via Bologna 148, 10154 Torino, Italy. ${ }^{2}$ Dipartimento di Patologia Animale Facoltà di Medicina Veterinaria dell'Università degli studi di Torino, Via Leonardo Da Vinci 44, 10095 Grugliasco (TO), Italy. ${ }^{3}$ Reparto Animali da laboratorio - Istituto Zooprofilattico Sperimentale della Lombardia e dell'Emilia Romagna, Via Bianchi 7/9 - 25124 Brescia, Italy.

\section{Authors' contributions}

PLA conceived and led the project, interpreted the genetics and drafted the manuscript; FM prepared the inoculum, assisted in sample collection, performed PrPSC quantification, and contributed to the manuscript; ADA carried out the neurological clinical evaluations, interpreted the clinics, and contributed to the manuscript; SP assisted in observation of the animals, sample collection, and interpreting the results of genetics; SC carried out the genetic analysis to find the animals and kept the database and records; CM performed the statistical analysis and contributed to the manuscript; CP carried out the immunohistochemistry; $\mathrm{Bl}$ assisted in sample collection and interpreting the immunohistochemistry results; MM interpreted the immunoblot results; LDA carried out the immunoblot analysis; FZ assisted in observation of the animals; CC prepared the inoculum and assisted in sample collection; NM managed daily observation of the animals and assisted in sample collection; CC interpreted the immunohistochemistry results; $M C$ contributed to the manuscript; GL inoculated the animals and was responsible for their care. All the authors read and approved the final manuscript.

\section{Competing interests}

The authors declare that they have no competing interests.

Received: 4 October 2011 Accepted: 1 February 2012

Published: 1 February 2012 
References

1. Prusiner SB: Molecular biology of prion diseases. Science 1991 252:1515-1522.

2. Chelle PL: Un cas de tremblante chez la chèvre. Bull Acad Vet Fr 1942 15:294-295 (in French).

3. Vaccari G, Panagiotidis C, Acín C, Peletto S, Barillet F, Acutis PL, Bossers A, Langeveld J, van Keulen L, Sklaviadis T, Badiola JJ, Andreoletti O, Groschup MH, Agrimi U, Foster J, Goldmann W: State-of -the -art review of goat TSE in the European Union, with special emphasis on PRNP genetics and epidemiology. Vet Res 2009, 40:48.

4. Eloit M, Adjou K, Coulpier M, Fontaine JJ, Hamel R, Lilin T, Messiaen S, Andreoletti $O$, Baron T, Bencsik A, Biacabe AG, Beringue $V$, Laude $H$, Le Dur A, Vilotte JL, Comoy E, Deslys JP, Grassi J, Simon S, Lantier F, Sarradin P: BSE agent signatures in a goat. Vet Rec 2005, 156:523-524.

5. Jeffrey M, Martin S, Gonzalez L, Foster J, Langeveld JPM, van Zijderveld FG, Grassi J, Hunter N: Immunohistochemical features of $\mathrm{PrP}^{\mathrm{d}}$ accumulation in natural and experimental goat transmissible spongiform encephalopathies. J Comp Pathol 2006, 134:171-181.

6. Capucchio MT, Guarda F, Isaia MC, Caracappa S, Di Marco V: Natural occurence of scrapie in goats in Italy. Vet Rec 1998, , 143: 452-453.

7. Belt PB, Muileman $\mathrm{H}$, Schreuder BEC, Bos-de Ruijter J, Gielkens ALJ, Smits MA: Identification of five allelic variants of the sheep PrP gene and their association with natural scrapie. J Gen Virol 1995, 76:509-517.

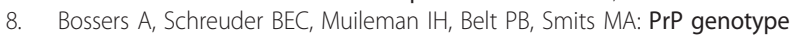
contributes to determining survival times of sheep with natural scrapie. J Gen Virol 1996, 77:2669-2673.

9. Hunter N, Foster JD, Goldmann W, Stear MJ, Hope J, Bostock C: Natural scrapie in a closed flock of Cheviot sheep occurs only in specific PrP genotypes. Arch Virol 1996, 141:809-824.

10. Hunter N, Cairns D, Foster JD, Smith G, Goldmann W, Donnelly K: Is scrapie solely a genetic disease? Nature 1997, 386:137

11. Fragkiadaki EG, Vaccari G, Ekateriniadou LV, Agrimi U, Giadinis ND, Chiappini B, Esposito E, Conte M, Nonno R: PRNP genetic variability and molecular typing of natural goat scrapie isolates in a high number of infected flocks. Vet Res 2011, 42:104.

12. Goldmann W, Chong A, Foster J, Hope J, Hunter N: The shortest known prion protein gene allele occurs in goats, has only three octapeptide repeats and is non-pathogenic. J Gen Virol 1998, 79:3173-3176.

13. Goldmann W, Martin T, Foster J, Hughes S, Smith G, Hughes K, Dawson M Hunter N: Novel polymorphisms in the caprine PrP gene: a codon 142 mutation associated with scrapie incubation period. J Gen Virol 1996, 77:2885-2891.

14. Barillet $F$, Mariat $D$, Amigues $Y$, Faugeras $R$, Caillat $H$, Moazami-Goudarzi $K$, Rupp R, Babillot JM, Lacroux C, Lugan S, Schelcher F, Chartier C, Corbière F, Andréoletti $\mathrm{O}$, Perrin-Chauvineau $\mathrm{C}$ : Identification of seven haplotypes of the caprine PrP gene at codons 127, 142, 154, 211, 222 and 240 in French Alpine and Saanen breeds and their association with classical scrapie. J Gen Virol 2009, 90:769-776.

15. González L, Martin S, Hawkins SA, Goldmann W, Jeffrey M, Sisó S: Pathogenesis of natural goat scrapie: modulation by host PRNP genotype and effect of co-existent conditions. Vet Res 2010, 41:48.

16. Vaccari , Di Bari MA, Morelli L, Nonno R, Chiappino B, Antonucci G, Marcon S, Esposito E, Fazzi P, Palazzini N, Troiano P, Petrella A, Di Guardo G, Agrimi U: Identification of an allelic variant of the goat PrP gene associated with resistance to Scrapie. J Gen Virol 2006, 87:1395-1402.

17. Billinis CH, Panagiotidis C, Psychas V, Argyroudis S, Nicolau A, Leontides S, Papadopoulos O, Sklaviadis T: Prion protein gene polymorphisms in natural goat scrapie. J Gen Virol 2002, 83:713-721.

18. Colussi S, Vaccari G, Maurella C, Bona C, Lorenzetti R, Troiano P, Casalinuovo F, Di Sarno A, Maniaci MG, Zuccon F, Nonno R, Casalone C, Mazza M, Ru G, Caramelli M, Agrini U, Acutis PL: Histidine at codon 154 of the prion protein gene is a risk factor for Nor98 scrapie in goats. $J$ Gen Virol 2008, 89:3173-3176

19. Papasavva-Stylianou $P$, Kleanthous M, Toumazos $P$, Mavrikiou P, Loucaides $P$ : Novel polymorphisms at codons 146 and 151 in the prion protein gene of Cyprus goats, and their association with natural scrapie. Vet J 2007 173:459-462

20. Papasavva-Stylianou P, Windl O, Saunders G, Mavrikiou P, Toumazos P, Kakoyiannis C: PrP gene polymorphisms in Cyprus goats and their association with resistance or susceptibility to natural scrapie. Vet J 2011, $187: 245-250$
21. Acutis PL, Bossers A, Priem J, Riina MV, Peletto S, Mazza M, Casalone C, Forloni G, Ru G, Caramelli M: Identification of prion protein gene polymorphisms in goats from italian scrapie outbreaks. J Gen Virol 2006 87:1029-1033.

22. Bouzalas IG, Dovas Cl, Banos G, Papanastasopoulou M, Kritas S, Oevermann A, Papakostaki D, Evangelia C, Papadopoulos O, Seuberlich T, Koptopoulos G: Caprine PRNP polymorphisms at codons 171, 211, 222 and 240 in a Greek herd and their association with classical scrapie. J Gen Virol 2010, 91:1629-1634.

23. EFSA Panel on Biological Hazards (BIOHAZ): Scientific Opinion on genetic TSE resistance in goats in all European Union Member States. EFSA Journal 2009, 7:1371-1412.

24. Acutis PL, Sbaiz L, Verburg F, Riina MV, Ru G, Moda G, Caramelli M, Bossers A: Low frequency of the scrapie resistance associated allele and presence of lysine-171 allele of the prion protein gene in Italian Biellese ovine breed. J Gen Virol 2004, 85:3165-3172.

25. Lombardi G, Casalone C, D'Angelo A, Gelmetti D, Torcoli G, Barbieri I, Corona C, Fasoli E, Farinazzo A, Fiorini M, Gelati M, Iulini B, Tagliavini F, Ferrari S, Caramelli M, Monaco S, Capucci L, Zanusso G: Intraspecies transmission of BASE induces clinical dullness and amyotrophic changes. PLoS Pathog 2008, 4:e1000075.

26. D'Angelo A, Maurella C, Bona C, Borrelli A, Caramelli M, Careddu EM, Jaggy $A, R u$ G: Assessment of clinical criteria to diagnose scrapie in Italy. Vet J 2007, 174:106-112.

27. Braun U, Kihm U, Pusterla N, Schönmann M: Klinischer Untersuchunsgang bei Verdacht auf bovine spongiforme Enzephalopathie (BSE). Schweiz Arch Tierheilkd 1997, 139:35-41, (in German).

28. Corona C, Porcario C, Martucci F, lulini B, Manea B, Gallo M, Palmitessa C, Maurella C, Mazza M, Pezzolato M, Acutis PL, Casalone C: Olfactory system involvement in natural scrapie disease. J Virol 2009, 83:3657-3667.

29. Harmeyer S, Pfaff E, Groschup MH: Synthetic peptide vaccines yield monoclonal antibodies to cellular and pathological prion proteins of ruminants. J Gen Virol 1998, 79:937-945

30. Hardt M, Baron T, Groschup MH: A comparative study of immunohistochemical methods for detecting abnormal prion protein with monoclonal and polyclonal antibodies. J Comp Pathol 2000, 122:43-53.

31. Foster JD, Parnham D, Chong A, Goldmann W, Hunter N: Clinical signs, histopathology and genetics of experimental transmission of BSE and natural scrapie to sheep and goats. Vet Rec 2001, 148:165-171.

32. Houston EF, Gravenor MB: Clinical signs in sheep experimentally infected with scrapie and BSE. Vet Rec 2003, 152:333-334.

33. Sofianidis G, Psychas V, Billinis C, Spyrou V, Argyroudis S, Papaioannou N, Vlemmas I: Histopathological and immunohistochemical features of natural goat scrapie. J Comp Pathol 2006, 135:116-129.

34. Konold T, Bone G, Simmons MM, Dexter G, Moore SJ, Pettitt RG: Scrapie in goats. Vet Rec 2007, 161:395-396.

35. Konold T, Bone GE, Phelan LJ, Simmons MM, González L, Sisó S, Goldmann W, Cawthraw S, Hawkins SAC: Monitoring of clinical signs in goats with transmissible spongiform encephalopathies. BMC Vet Res 2010, 6:13.

36. Valdez RA, Rock MJ, Anderson AK, O'Rourke Kl: Immunohistochemical detection and distribution of prion protein in a goat with natural scrapie. J Vet Diagn Invest 2003, 15:157-162.

37. Sharpe A, McElroy M, Bassett H, Sweeney T: Clinical and pathological features of experimental scrapie in Irish Blackface Mountain sheep. Res Vet Sci 2006, 80:71-78.

38. Ligios C, Cancedda GM, Margalith I, Santucciu C, Madau L, Maestrale C, Basagni M, Sala M, Heikenwalder M: Intraepithelial and interstitial deposition of pathological prion protein in kidneys of scrapie-affected sheep. PLoS One 2007, 2:e859.

39. Monleón E, Garza MC, Sarasa R, Álvarez-Rodriguez J, Bolea R, Monzón M, Vargas MA, Badiola JJ, Acín C: An assessment of the efficiency of PrPsC detection in rectal mucosa and third-eyelid biopsies from animals infected with scrapie. Vet Microbiol 2011, 147:237-243.

40. Ryder S, Dexter G, Bellworthy S, Tongue S: Demonstration of lateral transmission of scrapie between sheep kept under natural conditions using lymphoid tissue biopsy. Res Vet Sci 2004, 76:211-217.

41. Espenes A, McL Press C, Landsverk T, Tranulis MA, Aleksandersen M, Gunnes G, Benestad SL, Fuglestveit R, Ulvund MJ: Detection of $\operatorname{PrP}(\mathrm{Sc})$ in 
rectal biopsy and necropsy samples from sheep with experimental scrapie. J Comp Pathol 2006, 134:115-125.

42. Pattison IH, Millson GC: The distribution of the scrapie agent in the tissues of experimentally inoculated goats. J Comp Pathol Ther 1962 72:233-244.

43. EFSA Panel on Biological Hazards (BIOHAZ): Scientific Opinion on BSE/TSE infectivity in small ruminant tissues. EFSA Journal 2010, 8:1875.

44. Nonno R, Esposito E, Vaccari G, Conte M, Marcon S, Di Bari M, Ligios C, Di Guardo G, Agrimi U: Molecular analysis of cases of Italian sheep scrapie and comparison with cases of bovine spongiform encephalopathy (BSE) and experimental BSE in sheep. J Clin Microbiol 2003, 41:4127-4133.

45. Acutis PL, Martucci F, Mazza M, Nodari S, Maurella C, Ru G, Casalone C, Caramelli M: Molecular typing of small ruminant TSE cases from Italian outbreaks. Vet Rec 2006, 159:746-747.

46. Eiden M, Soto EO, Mettenleiter TC, Groschup MH: Effects of polymorphisms in ovine and caprine prion protein alleles on cell-free conversion. Vet Res 2011, 42:30.

47. Bouzalas IG, Lörtscher F, Dovas Cl, Oevermann A, Langeveld JP, Papanastassopoulou M, Papadopoulos O, Zurbriggen A, Seuberlich T: Distinct proteinase K-resistant prion protein fragment in goats with no signs of disease in a classical scrapie outbreak. J Clin Microbiol 2011 49:2109-2115.

48. Baylis M, Goldmann W: The genetics of scrapie in sheep and goats. Curr Mol Med 2004, 4:385-396.

49. Dickinson AG, Fraser $\mathrm{H}$ : An assessment of the genetics of scrapie in sheep and mice. In Slow Transmissible Diseases of the Nervous System. Volume 1. Edited by: Prusiner SB, Hadlow WJ. Academic Press, New York: 1979:367-385.

doi:10.1186/1297-9716-43-8

Cite this article as: Acutis et al:: Resistance to classical scrapie in experimentally challenged goats carrying mutation K222 of the prion protein gene. Veterinary Research 2012 43:8.

\section{Submit your next manuscript to BioMed Central} and take full advantage of:

- Convenient online submission

- Thorough peer review

- No space constraints or color figure charges

- Immediate publication on acceptance

- Inclusion in PubMed, CAS, Scopus and Google Scholar

- Research which is freely available for redistribution

Submit your manuscript at www.biomedcentral.com/submit
Biomed Central 